Original Article

\title{
Pattern of Skull Fractures and Its Outcome in Pediatric Head Injury Patients
}

\author{
Ghulam Muhammad, Farrukh Javeed, Lal Rehman, Asad Abbas, Ali Afzal \\ Department of Neurosurgery, Jinnah Postgraduate Medical Centre, Karachi - Pakistan
}

\begin{abstract}
Objective: Skull fractures are common in the pediatric age group. The surgical management of pediatric patients with skull fractures differs among institutions and surgeons. Our object of this study was to assess the pattern of skull fractures and outcome in the pediatric population.

Material and Methods: This study was conducted in the department of neurosurgery of a tertiary care hospital from June 2018 to April 2020. We included 152 children between ages 5 to 11 years who were brought with head trauma and diagnosed to have a skull fracture on computerized tomography (CT) Scan brain.

Results: The mean age of patients was $6.91 \pm 1.84$ years. Out of those, $59.8 \%$ were male and $40.1 \%$ were female. The most common type of fracture at presentation was depressed fracture in $42 \%$ patients, followed by linear (35\%) and compound fractures (23\%). Parietal fractures were the commonest $(63.1 \%)$ in our study. Associated intracranial hematomas were seen in $37.5 \%$ patients, epidural hematoma being the most common. Surgically treated patients were $36 \%$. Good recovery was seen in $73 \%$ patients while mortality was $10.5 \%$.
\end{abstract}

Conclusion: Isolated skull fractures are overall benign conditions. Linear parietal skull fractures have good outcomes amongst all fracture types.

Keywords: Head Injury, Skull fracture, Glasgow coma score, Traumatic brain injury, Glasgow outcome scale.

\section{Corresponding Author: Farrukh Javeed \\ Department of Neurosurgery, \\ Jinnah Postgraduate Medical Centre \\ Rafiqui Shaheed Road, Karachi, Pakistan \\ Email: farrukhjavedkhi@gmail.com}

Date of Submission: 10-11-2020

Date of Revision: 15-12-2020

Date of Online Publishing: 25-12-2020

Date of Print: 30-12-2020

DOI: $10.36552 /$ pjns.v24i4.485

\section{INTRODUCTION}

Head trauma among the pediatric population is not an uncommon entity and causes a significant amount of morbidity and mortality. Head trauma is dealt according to the initial clinical status and underlying skull and brain findings. Clinical status is determined according to different grading systems and Glasgow coma score (GCS) is one of the commonest initial assessment systems. Radiological investigations are needed to assess

Pak. J. of Neurol. Surg. -2020 - 24 (4): 350-356. 
the underlying skull and brain injuries. Skull radiographs can be used as the initial investigation in minor pediatric head injuries, but it can only predict the skull fractures to some extent and also can't unveil the underlying brain injuries. $^{1,2}$

Computed Tomography (CT) scan is the investigation of choice to diagnose the skull fractures. A CT scan can diagnose the type of fractures like a linear or depressed and also associated cerebral injury (Figure 1). But there are guidelines to be used to undergo CT scan for pediatric head trauma, especially in the cases where patients are neurologically intact and radiograph shows skull fracture. ${ }^{3}$ There is one school of thought that neurologically stable patients with simple linear fractures can be observed or discharged to home after initial treatment in the emergency department without any further neurosurgical intervention., ${ }^{4,5}$

Along with the skull fractures, associated

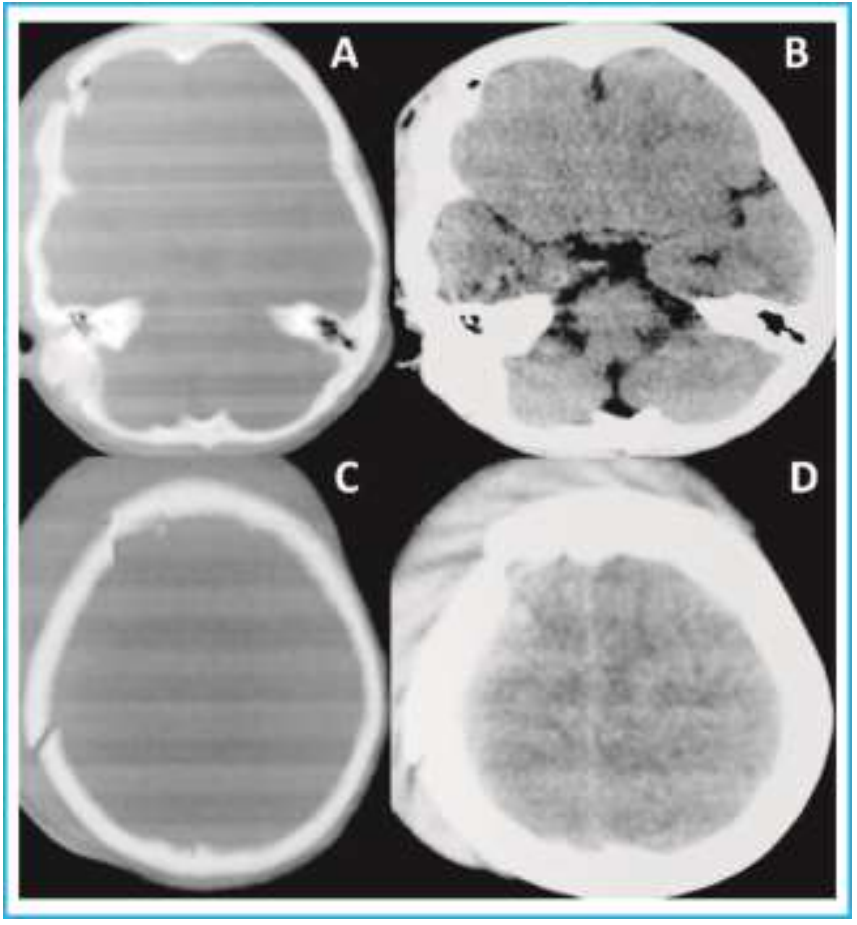

Figure 1: Depressed fracture (A) with no underlying hematoma (B), Depressed fracture (C) with underlying cerebral Contusion (D). cerebral injuries can have a significant impact on the outcome of the patients. Common associated intracranial injuries are epidural hematomas, subdural hematomas, cerebral contusions and dural tears. Such associated intracranial findings can alter the prognosis. The primary use of CT scans for suspected fractures and intracranial injuries can save the time and radiological exposure specially with neurologically symptomatic patients. ${ }^{6,7}$ So, CT scans in pediatric skull fractures can predict the adverse outcome and prognosis. $^{8}$ Physical findings in pediatric patients can be altered mentation, repeated vomiting, seizures, open scalps wounds, signs of basilar skull fractures and neurological deficits.

Management of skull fractures depends on the type of fracture as well as associated intracranial injuries. Depressed fracture and significant size of hematoma are usually treated surgically. Water-tight dural closure in case of dural tear is an important factor in the prevention of infections. There are few complications associated with pediatric skull fractures like neurological deficit, seizures, cerebrospinal fluid (CSF) leak, meningitis and infections. Neurological deficit can be seen in $33 \%$ of patients out of which less than half of patients developing permanent deficit. $^{9}$ Improvement from preoperative neurological deficit is about $7.05 \%$ following operative repair and medical management. ${ }^{10}$ Outcome is good in pediatric skull fractures with $86 \%$ discharged to home and only $14 \%$ with the poor outcome. ${ }^{9}$ The study was to focus on the evaluation of the clinical outcome of skull fractures in children. Several studies in the literature have shown a wide range of outcomes in children with skull fractures."11 However, the local data is still lacking and our study will be an attempt to report the local data from a tertiary care hospital. 
MATERIALS AND METHODS

\section{Study Setting \& Design}

Our study was conducted at the Neurotrauma unit of the Neurosurgery department in Jinnah Postgraduate Medical Centre (JPMC), Karachi from June 2018 to April 2020. It was a cross sectional study with consecutive non-probability sample.

\section{Inclusion Criteria}

Our study included all the pediatric head trauma patients of ages between five to 11 years of either gender with skull fracture diagnosed on the CT scan head. Our study included children with a previous history of brain pathologies or brain surgery, penetrating skull injuries.

\section{Exclusion Criteria}

Major chest/abdominal trauma or known bleeding disorders were excluded from the study.

\section{Data Collection}

The data was collected after institutional review board approval and informed consent. All the children with head trauma underwent $C T$ scan brain plain after initial history and examination by the neurosurgery resident having at least two years' experience and then admitted in the neurosurgery high dependency unit (HDU) or intensive care unit (ICU). There was no separate dedicated pediatric HDU/ICU unit in our department and pediatric patients were traditionally managed by the general neurosurgery team here. Data regarding the age, gender, mechanism of head trauma, initial Glasgow coma scale (GCS), CT scan findings (type of skull fracture and associated intracranial hemorrhage), type of treatment and outcome was collected. On the basis of GCS, Traumatic brain injury (TBI) was categorized into mild (GCS 13 $15)$, moderate (GCS $9-12$ ) and severe ( $G C S \leq 8)$.
Surgeries (where indicated) were performed by an independent neurosurgeon or a neurosurgery resident of at least 5 year experience with a pediatric anesthetist of at least 5 year experience. All operated cases underwent repeat CT scan brain within 24 hours of surgery. Data was stratified to deal with confounding factors such as age, gender and type of fracture.

\section{Follow-up}

Patients were followed for three months from the head trauma. The outcome was calculated according to Glasgow outcome score (GOS); GOS 1 (mortality), GOS 2 (vegetative state), GOS 3 (severe disability), GOS 4 (moderate disability) and GOS 5 (good recovery). Outcome was categorized into a good outcome (GOS score 5) and poor outcome (GOS score from 1 to 4).Mean and standard deviation was calculated for quantitative variables like age and initial GCS.

\section{Data Analysis}

Frequency and percentages were calculated for qualitative variables like gender, mechanism of head trauma, type of skull fracture, associated intracranial hemorrhage, type of treatment and outcome. Chi square test was applied and $p \leq 0.05$ was taken as significant.

\section{RESULTS}

After matching the inclusion and exclusion criteria, we enrolled a total number of 152 patients who gave consent to participate in the study.

\section{Age Incidence}

The mean age of patients was $6.91 \pm 1.84$ years.

\section{Gender Distribution}

There were 91 (59.8\%) males and 61 (40.1\%) females. 


\section{Mechanism of Injury}

The commonest mechanism of head trauma was fall in 77 (50.6\%) patients, followed by road traffic accidents (RTA) in 56 (36.8\%) and other mechanisms of injury in 19 (12.5\%) patients.

\section{Severity of TBI}

Mild TBI was seen in 77 (50.6\%), moderate TBI in 45 (29.6\%) and severe TBI in 30 (19.7\%) patients.

\section{Type and Location of Fracture}

The most common type of fracture at presentation was depressed fracture in 64 (42.1\%) patients, followed by linear and compound fractures (Figure 2). The majority of the fractures were involving parietal bone in 96 (63.1\%) patients, others involved occipital (17.7\%), frontal (12.5\%), temporal (4.6\%) and skull base (1.9\%).

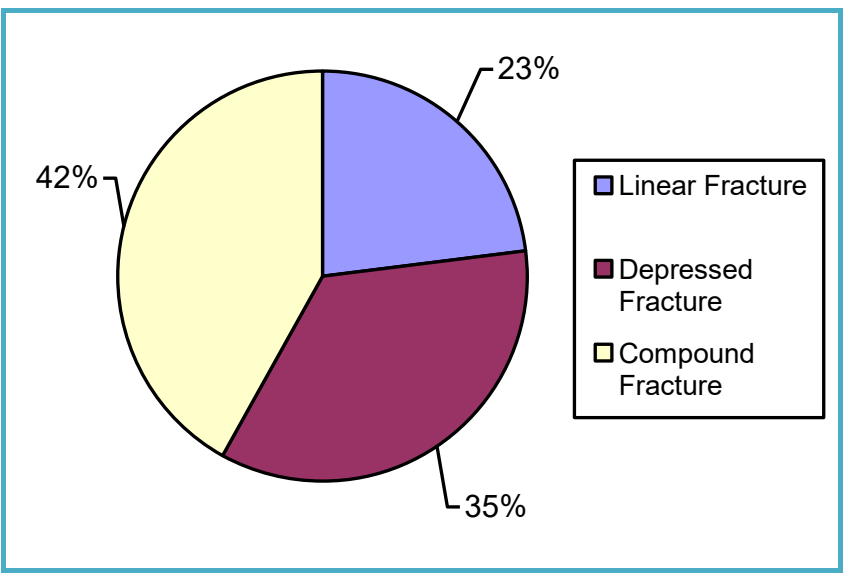

Figure 2: Types of skull fractures.

\section{Associated Intracranial Injury}

We found that associated intracranial hematomas in pediatric head injury patients with skull fractures were seen in 57 (37.5\%), commonest hematoma was epidural hematoma (EDH) in 32 patients but other hematomas like cerebral contusion, subarachnoid hemorrhage (SAH), subdural hematoma (SDH) and intraventricular hematoma (IVH) were also observed (Figure 3).

\section{Treatment}

Surgical intervention was done in 55 (36.2\%) patients while remaining 97 (63.8\%) were managed non-surgically. All surgeries (55) were

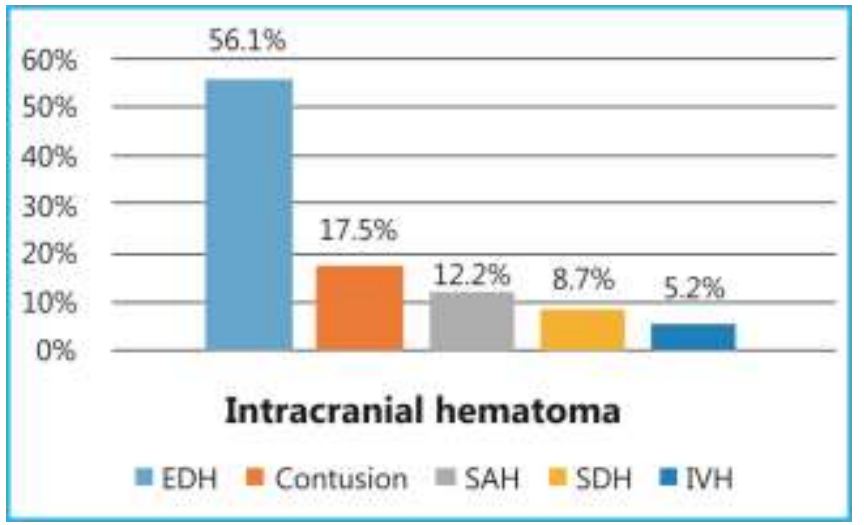

Figure 3: Intracranial hematomas associated with skull fractures.

performed within 24 to 48 hours of the head trauma, $65.4 \%$ of these performed within 12 hours. Only three patients underwent repeat surgery for CSF leak (two patients) and post-op hematoma (one patient). Average operative time was 90 minutes and average blood loss during surgery was $65 \mathrm{ml}$.

\section{Outcome \& Complications}

Good recovery was observed in 111 (73.0\%)

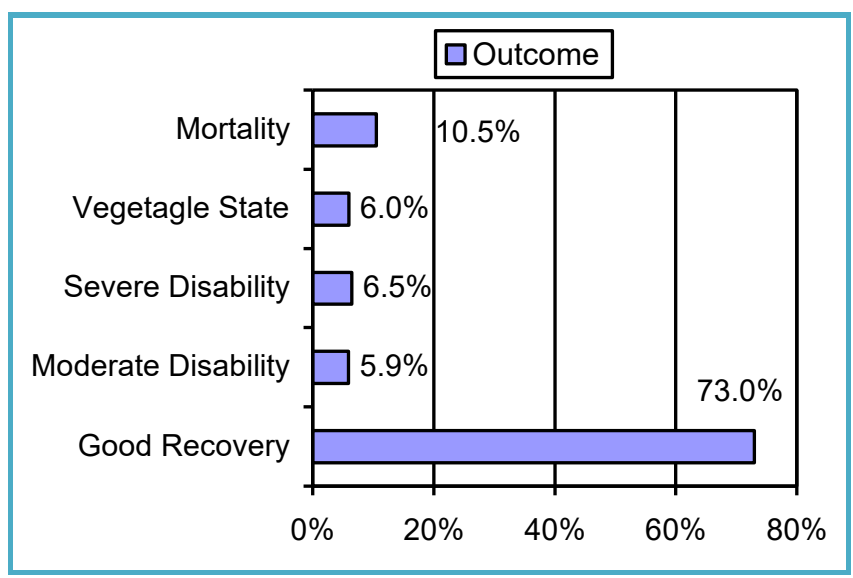

Figure 4: Outcome of pediatric skull fractures. 
patients while mortality was $10.5 \%$ (Figure 4). Complications were observed in 31 (20.4\%) patients (Figure 5).

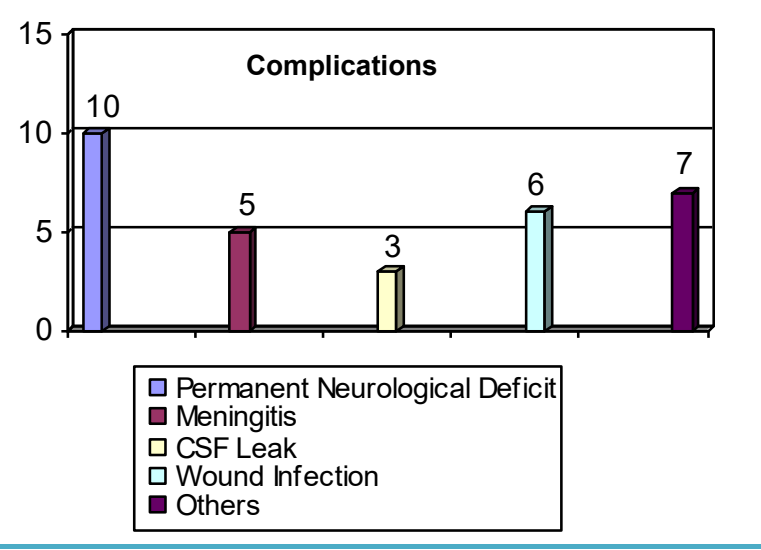

Figure 5: Complications in skull fractures.

There was no significant relationship between the location or skull fracture and outcome in our study ( $p$-value $>0.05$ ) (See Table 1).

Table 1: Outcome according to type of fracture.

\begin{tabular}{lcccc|} 
& $\begin{array}{c}\text { Good } \\
\text { Outcome }\end{array}$ & $\begin{array}{c}\text { Outcome } \\
\text { Poor } \\
\text { Outcome }\end{array}$ & Total & P value \\
$\begin{array}{l}\text { Linear } \\
\text { fracture }\end{array}$ & 47 & 6 & 53 & \\
$\begin{array}{l}\text { Depressed } \\
\text { fracture }\end{array}$ & 45 & 19 & 64 & $<0.05$ \\
$\begin{array}{l}\text { Compound } \\
\text { fracture }\end{array}$ & 19 & 16 & 35 & \\
Total & 111 & 41 & 152 & \\
\hline
\end{tabular}

Table 2: Outcome with respect to associated intracranial hematomas.

\begin{tabular}{|c|c|c|c|c|}
\hline & \multicolumn{3}{|c|}{ Outcome } & \multirow{2}{*}{$\begin{array}{c}\mathbf{P} \\
\text { value }\end{array}$} \\
\hline & $\begin{array}{c}\text { Good } \\
\text { Outcome }\end{array}$ & $\begin{array}{c}\text { Poor } \\
\text { Outcome }\end{array}$ & Total & \\
\hline $\begin{array}{l}\text { Intracranial } \\
\text { hematoma }\end{array}$ & 31 & 26 & 57 & \multirow{3}{*}{$<0.05$} \\
\hline $\begin{array}{l}\text { No intracranial } \\
\text { hematoma }\end{array}$ & 80 & 15 & 95 & \\
\hline Total & 111 & 41 & 152 & \\
\hline
\end{tabular}

According to our data, the possibility of poor outcome in pediatric skull fractures was more if there was associated intracranial hematoma ( $p$-value <0.05) given in Table 2.

\section{DISCUSSION}

Skull fracture is one common presentation in pediatric head injury. Our study observed that almost two-third of patients with skull fractures were male. The literature has shown a consistent male preponderance. ${ }^{3,7,13}$ The reason for this gender disparity is that male children are more commonly involved in contact sports. The mean age in our patients was 6.91 years while another study showed the mean age of children as 5.9 years. ${ }^{7}$ Fall was the commonest mechanism of head trauma, with about half of the total patients in our study. Children younger than two years of age are more commonly presented with a history of fall because of weaker bones and a less developed sense of self care.Studies by Powell et al (70\%) and Arneitz et al (79\%) also showed similar results with fall being the commonest cause. $^{4,7}$

Half of our studied patients had mild TBI and one-fifth presented with severe TBI. One study showed a similar presentation with mild TBI being the most common. ${ }^{14}$ Depressed fracture was the common type with almost half of the patients presenting with it and compound fracture being least common in our study. Steinbok et al in his published article showed that $42.3 \%$ of depressed fractures were compound fractures. ${ }^{15}$ Parietal fractures were seen in about two-third of our patients with occipital and frontal fractures being other common sites. Other studies also showed that parietal being the commonest fracture site. $^{7,13}$

Two thirds of the patients in our study presented with no intracranial hematoma and only one third had one or other type of hematoma. Patients with intracranial hematomas had $\mathrm{EDH}$ in the majority. Literature review showed 
varying degrees of associated intracranial hematomas ranging from $14 \%$ to $45.3 \%{ }^{7,13}$ About two-third of our patients were managed nonsurgically and only about one-third patients were dealt surgically. Bonfield et al in his study showed that the majority (86.1\%) of their patients were managed conservatively. ${ }^{13}$

The outcome in our study was good in the majority of our patients. About one-fourth of our patients had poor outcome and graded I to IV on the GOS. The mortality rate in our studied population was $10.5 \%$. One-fifth of our patients showed complications. The most common complication was a permanent neurological deficit in 10 patients, out of which five had weakness of limbs, two had speech difficulties and two had visual deficits and one with anosmia.

In our study, we found that the severity of TBI (initial GCS of patient) had a significant impact ( $p$ value $<0.05$ ) on the outcome of skull fractures with severe TBI showing higher chances of poor outcome. Early prediction of intracranial injury or late development of intracranial findings and ultimately the outcome is difficult in children when patients are neurologically intact at presentation. ${ }^{16,17}$ Type of skull fractures compared with the outcome in pediatric head injury showed that compound fractures had the poorest outcome than the depressed and linear fractures ( $p$-value < 0.05). There was no significant relationship between the location or skull fracture and outcome in our study ( $p$-value $>0.05$ ).

According to our data, the possibility of poor outcome in pediatric skull fractures was more if there was associated intracranial hematoma $(p-$ value $<0.05$ ). Surgical or non-surgical treatment showed no considerable difference on the outcome of skull fracture patients ( $p$-value $>0.05$ ). The need for surgical intervention in skull fractures is not necessary for the depressed skull fracture itself, but frequently be carried out for the associated underlying injuries.

\section{CONCLUSION}

Skull fractures in pediatric patients generally have good outcome, but the severity of traumatic brain injury, compound fractures and associated intracranial hematoma can have profound effects on the overall outcome and mortality.

\section{REFERENCES}

1. Lloyd DA, Carty H, Patterson M, Butcher CK, Roe D. Predictive value of skull radiography for intracranial injury in children with blunt head injury. Lancet. 1997; 349: 821-4.

2. Mossop D, Soysa $S$. The use of skull X-rays in head injury in the emergency department - A changing practice. Ann R Coll Surg Engl. 2005; 87: 188-90.

3. Palchak MJ, Holmes JF, Vance CW, Gelber RE, Schauer BA, Harrison MJ, et al. A decision rule for identifying children at low risk for brain injuries after blunt head trauma. Ann Emerg Med. 2003; 42: 492-506.

4. Powell EC, Atabaki SM, Wootton-Gorges S, Wisner D, Mahajan P, Glass T, Miskin $M$, Stanley RM, Jacobs E, Dayan PS, Holmes JF, Kuppermann N. Isolated linear skull fractures in children with blunt head trauma. Pediatrics, 2015; 135 (4): e851-7.

Doi: 10.1542/peds.2014-2858.

5. Metzger RR, Smith J, Wells M, Eldridge L, Holsti M, Scaife ER, et al. Impact of newly adopted guidelines for management of children with isolated skull fracture. J Pediatr Surg. 2014; 49; 1856-60.

6. Culotta PA, Crowe JE, Tran QA, Jones JY, MehollinRay AR, Tran HB, et al. Performance of computed tomography of the head to evaluate for skull fractures in infants with suspected non-accidental trauma. Pediatr Radiol. 2017; 47 (1): 74-81.

7. Arneitz $C$, Sinzig $M$, Fasching $G$. Diagnostic and Clinical Management of Skull Fractures in Children. J Clin Imaging Sci. 2016; 16 (6): 47. Doi: 10.4103/2156-7514.194261.

8. Perheentupa U, Kinnunen I, Grénman R, Aitasalo K, Mäkitie AA. Management and outcome of pediatric skull base fractures. Int J Pediatr Otorhinolaryngol. 2010; 74 (11): 1245-50.

9. Tunik MG, Powell EC, Mahajan P, Schunk JE, Jacobs $\mathrm{E}$, Miskin $\mathrm{M}$, et al. Clinical presentations and 
outcomes of children with basilar skull fractures after blunt head trauma. Ann Emerg Med. 2016; 68 (4): 431-40.

10. Vezina N, Al-Halabi B, Shash $H$, Dudley RR, Gilardino MS. A Review of Techniques Used in the Management of Growing Skull Fractures. J Craniofac Sur. 2017; 28 (3): 604-9.

11. Zulfiqar $M$, Kim S, Lai JP, Zhou Y. The role of computed tomography in following up pediatric skull fractures. Am J Surg. 2016; 16: 7: 20.

12. Hassan SF, Cohn SM, Admire J, Nunez-Cantu O, Arar Y, Myers JG, et al. Natural history and clinical implications of non-depressed skull fracture in young children. J Trauma Acute Care Surg. 2014; 77 (1): 166-9.

13. Bonfield CM, Naran S, Adetayo OA, Pollack IF, Losee JE. Pediatric skull fractures: the need for surgical intervention, characteristics, complications, and outcomes. J Neurosurg Pediatr. 2014; 14 (2):
205-11. Doi: 10.3171/2014.5.PEDS13414.

14. Al-Haddad SA, Kirollos R. A 5-year study of the outcome of surgically treated depressed skull fractures. Ann R Coll Surg Engl. 2002; 84 (3): 196200.

15. Steinbok P, Flodmark O, Martens D, Germann ET. Management of simple depressed skull fractures in children. J Neurosurg. 1987; 66 (4): 506-10.

Doi: 10.3171/jns.1987.66.4.0506.

16. Reid SR, Liu M, Ortega HW. Non-depressed linear skull fractures in children younger than 2 years: Is computed tomography always necessary? Clin Pediatr (Phila). 2012; 51: 745-9.

17. Kuppermann N, Holmes JF, Dayan PS, Hoyle JD Jr., Atabaki SM, Holubkov $R$, et al. Identification of children at very low risk of clinically-important brain injuries after head trauma: A prospective cohort study. Lancet, 2009; 374: 1160-70.

\section{Additional Information}

Disclosures: Authors report no conflict of interest.

Ethical Review Board Approval: The study was conformed to the ethical review board requirements.

Human Subjects: Consent was obtained by all patients/participants in this study.

\section{Conflicts of Interest:}

In compliance with the ICMJE uniform disclosure form, all authors declare the following:

Financial Relationships: All authors have declared that they have no financial relationships at present or within the previous three years with any organizations that might have an interest in the submitted work.

Other Relationships: All authors have declared that there are no other relationships or activities that could appear to have influenced the submitted work.

\section{AUTHORS CONTRIBUTIONS}

\begin{tabular}{|l|l|l|}
\hline.$\#$ & Author's Full Name and Affiliation & Intellectual Contribution to Paper in Terms of: \\
\hline 1. & Ghulam Muhammad & 1. Study design and methodology. \\
\hline 2. & Farrukh Javeed & 2. Paper writing, referencing and data calculations. \\
\hline 3. & Lal Rehman & 3. Data collection and calculations. \\
\hline 4. & Asad Abbas & 4. Analysis of data and interpretation of results. \\
\hline 5. & Ali Afzal & 5. Literature review and manuscript writing \\
\hline
\end{tabular}

